\title{
A STUDY OF KUGEL'S ARTERY IN A POPULATION OF SOUTH KERALA
}

\author{
T. K. Kumari' ${ }^{1}$ P. S. Sajey², R. Rajad ${ }^{3}$
}

${ }_{1}^{1}$ Professor, Department of Anatomy, Government T. D. Medical College, Alappuzha, Kerala. ${ }^{2}$ Assistant Professor, Department of Anatomy, Government T.D Medical College, Alappuzha, Kerala. ${ }^{3}$ Assistant Professor, Department of Anatomy, Government T.D Medical College, Alappuzha, Kerala.

\begin{tabular}{l}
\hline ABSTRACT \\
BACKGROUND \\
Kugel's artery or 'arteria anastomotica auricularis magna' was described by Kugel (1927) as a constant branch from the circumflex \\
coronary artery usually from its anterior part traversing the interatrial septum to establish direct or indirect anastomosis with the \\
right coronary artery. Presence of Kugel's artery is a controversy. Many text books do not describe the artery and hence the \\
present study was conducted to confirm the presence of this artery.
\end{tabular}

Aim of this study is to find out the incidence of Kugel's artery in a population of South Kerala.

\section{MATERIALS AND METHODS}

Human cadaveric hearts were used. Dissected out 41 hearts, in the Department of Anatomy, Govt. Medical College, Thiruvananthapuram and Govt. T.D. Medical College, Alappuzha. Duration of study was one year. Intact hearts were used. Distorted hearts were excluded. Dissected the left coronary artery and the circumflex artery and searched for the first branch of the circumflex artery.

\section{RESULTS}

Observed the presence of Kugel's artery. Photographs were taken to confirm the observation. Presence of Kugel's artery in a population of South Kerala is $20 \%$.

\section{CONCLUSION}

Occurrence of Kugel's artery is confirmed. The artery may act as a collateral circulation when the arteries it connects.

\section{KEYWORDS}

Collateral Circulation, Kugel's Artery.

HOW TO CITE THIS ARTICLE: Kumari TK, Sajey PS, Rajad R. A study of Kugel's artery in a population of South Kerala. J. Evolution Med. Dent. Sci. 2017;6(8):612-614, DOI: 10.14260/Jemds/2017/131

\section{BACKGROUND}

The arterial supply of the heart is important owing to the peculiarity in terms of end arteries which execute the same and thereby the vulnerability of the heart tissue to ischaemia due to partial or complete obstruction of these arteries. The right coronary artery and its posterior interventricular branch, the left coronary artery and its left anterior interventricular and circumflex branches are the mainstay of arterial supply to the heart through their atrial, ventricular and nodal rami. Extensive studies are there in cardiologic literature on major branches which supply the ventricular musculature and the nodal arteries namely sinoatrial and atrioventricular arteries. The studies regarding the atrial rami are comparatively less with the exception to the one so called 'Kugel's artery' even though controversies are there with the existence of the same.

Financial or Other, Competing Interest: None.

Submission 14-12-2016, Peer Review 12-01-2017,

Acceptance 19-01-2017, Published 25-01-2017.

Corresponding Author:

Dr. T. K. Kumari,

'Devasaras'

Sreekaryam P. 0 .

Thiruvananthapuram-605017,

Kerala.

E-mail:drtkkumari@gmail.com

DOI: $10.14260 /$ jemds $/ 2017 / 131$
Kugel's artery or 'arteria anastomotica auricularis magna' was described by Kugel (1927) as a constant branch from the circumflex artery usually from its anterior part traversing the interatrial septum to establish direct or indirect anastomosis with the right coronary artery. Kugel's artery runs through the atrial septum which links the anterior coronary arteries to the posterior ventricular coronary tree. Kugel called this artery "arteria anastomotica auricularis magna" because of its large calibre, its important anastomotic role, and its consistent occurrence at this site. The two other variations described by him are the ones originating from the right coronary artery or its branch, AV nodal artery and that originating from the left circumflex artery that splits into smaller branches which connect to similar small branches coming from the right coronary artery at the crux level. ${ }^{1}$ Even though Kugel described this as a large anastomotic blood vessel which runs in the auricular wall and links up the left and right coronary arteries it was not simple to demonstrate it in post-mortem angiography and was extremely difficult to see in coronary angiograms in vivo. ${ }^{2}$ Workers like James ${ }^{3}$ and McAlpin ${ }^{4}$ did not accept the existence of such an artery in their anatomical studies as described by Kugel. In contrast, they described small atrial branches that arose from either the Left Circumflex or the Right Coronary Artery, or from both arteries, and connected with one another or with other small atrial branches from the surrounding area, then coursed posteriorly to the base of the interatrial septum and anastomosed with the atrioventricular node (AVN) artery. Despite these differences they still applied the term "Kugel's 
artery" to this network. According to Vasudeva Reddy and Lokanadham, it is a small communication branch between the left circumflex and right coronary artery. ${ }^{5}$

Highlighting the controversy and difference in opinions regarding the Kugel's artery Paolo Angelini comments this artery as the one which is frequently (but inconsistently) recognised in the literature with a specific name but no real definition. In this scenario, our aim is to check the existence of such an artery as described by Kugel which is arising from Circumflex coronary or right coronary which is passing through the corresponding atrial wall and interatrial septum towards the crux and thereby confirm the existence of Kugel's artery. The knowledge from these findings is important for Anatomists, Cardiologists and Cardiac surgeons. ${ }^{5}$

\section{Aim of Study}

To find out the incidence of Kugel's artery in a population of South Kerala.

\section{MATERIALS AND METHODS}

A total of 41 human cadaveric hearts were dissected and studied for finding out the presence of Kugel's artery of which 15 hearts were from the Department of Anatomy, Govt. Medical College, Thiruvananthapuram, Kerala. Rest 26 hearts were from Govt. T.D. Medical College, Alappuzha, Kerala. Duration of the study was one year. Intact hearts were used. Distorted hearts were excluded. The heart was removed from the thorax as per the methods described in the Cunningham's manual of practical Anatomy, vol 2. The area surrounding the root of aorta was cleared to find the initial parts of right and left coronary arteries. The left coronary artery was traced up to the point of bifurcation of left circumflex artery and anterior interventricular artery. Then, the circumflex coronary artery was dissected out carefully to delineate the first branch arising from it which passes towards the crux through the left atrial wall and interventricular septum. These branches were traced as far as distally and identified as Kugel's artery. The same procedure was done on the right side to find out whether there were branches from the right coronary artery which had similar destination. The relevant arteries were colour photographed and labelled.

\section{RESULTS}

The presence of Kugel's artery was observed. Among the dissected hearts, 8 showed Kugel's artery arising from the left circumflex artery and is its first branch. In 3 of the hearts, the Kugel's artery was seen to be arising from the posterior part of the left circumflex artery $1 \mathrm{~cm}$ after its origin from the left coronary artery. It then passed through the posterior part of the posterior aortic sinus and reached the interatrial septum. It travelled about $2.5 \mathrm{~cm}$ and disappeared. In one among the rest of the hearts the artery was found to be arising from the anterior part of the left circumflex $0.5 \mathrm{~cm}$ after its origin from the left coronary artery and followed the same course of the former. In the remaining 4 hearts, the Kugel's artery took origin from the lateral part of the left circumflex $1 \mathrm{~cm}$ after its origin from the left coronary artery and travelled through the posterior part of the posterior aortic sinus to the interatrial septum. All the branches were having a length of about 2.5 $\mathrm{cm}$.

Thus, 8 out of 40 hearts showed Kugel's artery as a prominent atrial ramus arising from the initial part of left circumflex coronary artery as its first branch. Thus, the incidence of Kugel's artery was found to be $20 \%$.

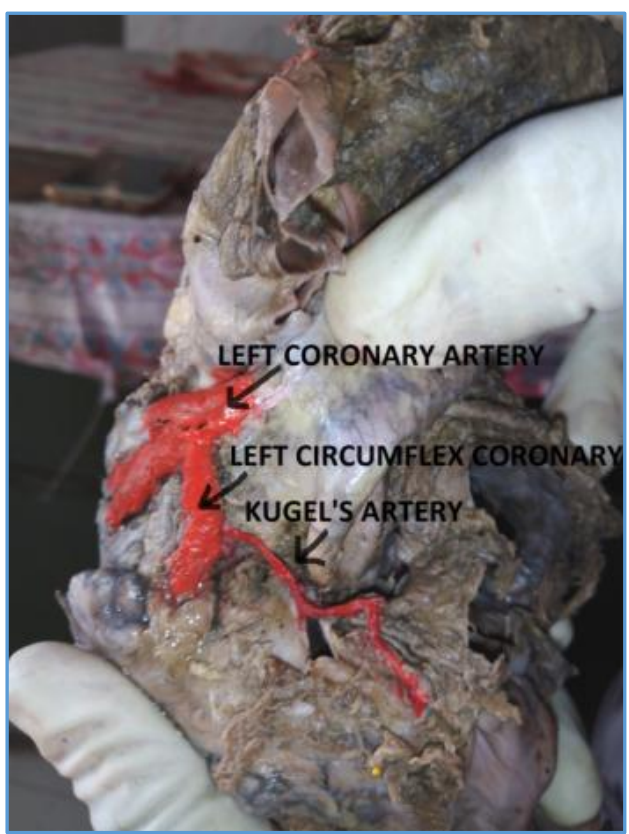

Figure 1

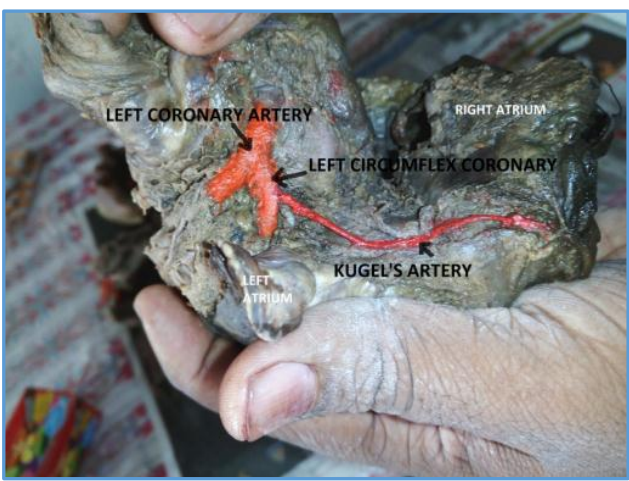

Figure 2

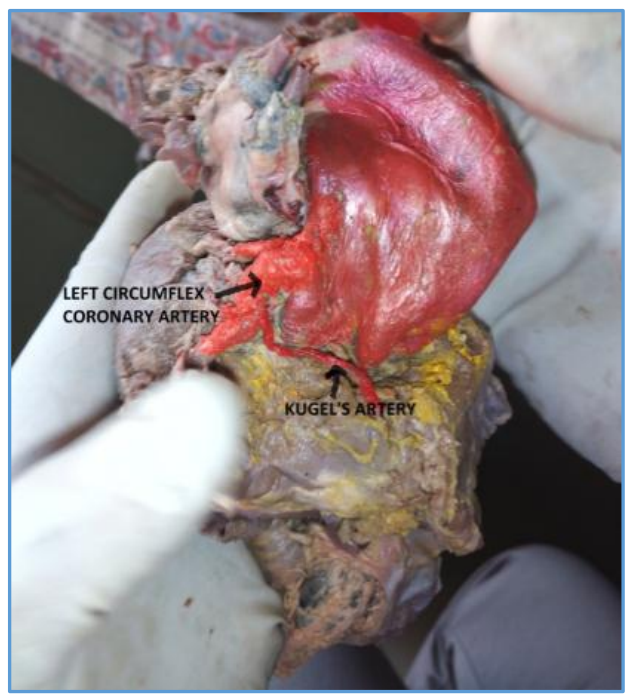

Figure 3 
As an artery which is frequently (but inconsistently) recognised in the literature with a specific name but no real definition, our primary aim was to check whether this artery is present or not. The existence of Kugel's artery is even questioned in Gray's Anatomy 39th Edition. Of the 41 dissected hearts, 8 showed Kugel's artery. It is seen as a slender branch arising as the first branch of the left circumflex artery. It travelled through the interatrial septum and disappears a little before the right coronary artery. The incidence was $20 \%$. The available incidence of Kugel's artery from literature is as follows - Grollman JH Jr and Heger LR ${ }^{6}$ (3.6\%), Vasudeva Reddy and Lokanadham S5 (3.75\%), Levin DC $^{7}(4.5 \%)$, Soto B et $\mathrm{al}^{8}(6 \%)$ and Narentzis Christos E et $\mathrm{al}^{2}$ (6\%). All these literatures were based on radiologic studies. The incidence of Kugel's artery is quite higher in anatomical studies, ranging between $40-66 \% .^{9}$ The lower incidence shown in radiological studies may be due to the fact that the workers consider the anastomosis of right coronary and left circumflex coronary artery for recognising the Kugel's artery. In our study, there was no visible anastomosis with the right coronary artery detected. According to studies using contrast media anastomotic channels are present. The Kugel's artery connects the anterior coronary artery (left main and circumflex) to the posterior coronary artery (right coronary). Its function might become apparent only in the event of a sudden occlusion of either of the two arteries it connects at which time their presence might decrease the ischaemic consequences. ${ }^{2}$ In this context, a small poorly organised vessel like Kugel's artery might also develop into a much larger vessel during days or months following such an occlusive event. Since Kugel's artery originates from the beginning of the coronary trunk it has to be taken into consideration in many surgical procedures involving the aortic root. Moreover, interventional cardiologists who perform procedures involving the lower part of interatrial septum such as radiofrequency ablation and biventricular pace maker insertion should be aware of the potential risk of damaging these important anastomotic branches. ${ }^{2}$ Extensive studies were not conducted by any of the authors. A reduced level of blood flow at the crux level is due to obstruction of right coronary and circumflex arteries. This fact suggests that Kugel's artery may function as an appropriate collateral channel.1
Occurrence of Kugel's artery is confirmed by dissection. The calibre of the artery we observed was large enough to act as a collateral circulation when there is occlusion of any one of the arteries it connects. The importance of atrial branches relates mainly to their potential as a source of collateral circulation in the event of acquired obstruction of the vessels with which they connect. ${ }^{2}$ So a prompt knowledge of communicating branches from the coronary vessels is very essential to the clinicians and surgeons. ${ }^{5}$ In this context more work is needed to study the detailed course and ramification of Kugel's artery which may act as a potential anastomotic channel.

\section{REFERENCES}

[1] Kugel MA. Anatomical studies on coronary arteries and their branches. American Heart Journal 1928;3(3):260-70.

[2] Christos NE, Marianou SK, Koulouris SN, et al. Kugel's Artery. An anatomical and angiographic study using a new technique. Texas Heart Institute Journal 2004;31(3):267-70.

[3] James TN. The delivery and distribution of coronary collateral circulation. Chest 1970;58(3):183-203.

[4] McAlpin WA. Heart and coronary arteries: an anatomical atlas for clinical diagnosis, radiological investigation, and surgical treatment. $1^{\text {st }}$ edn. New York: Springer-Verlag 1975: p. 151.

[5] Reddy VJ, Lokanadham S. An anomalous communication branch- Kugel's artery. International Journal of Current Research 2013;5(3);523-4.

[6] Grollman JH, Heger L. Angiographic anatomy of the left Kugel's artery. Cathet Cardiovasc Diagn 1978;4(2):127-33.

[7] Levin DC. Pathways and functional significance of the coronary collateral circulation. Circulation 1974;50:831-7.

[8] Soto. B, Jochem W, Karp KB, et al. Angiographic anatomy of the Kugel's Artery. American Journal of Roengenology 1973;119(3):503-7.

[9] Smith C, Amplatz K. Angiographic demonstration of Kugel's artery (arteria anastomotica auricularis magna). Radiology 1973;106(1):113-8.

\section{CONCLUSION}

